J. Lake Sci. (湖泊科学) , 2019, 31(4): 1055-1063

DOI 10. 18307/2019. 0409

(c) 2019 by Journal of Lake Sciences

\title{
城市湖泊不同水生植被区水体温室气体溶存浓度及其影响因素”
}

\author{
邓焕广, 张智博, 刘涛, 殷山红, 董 杰, 张 菊, 姚 昕 \\ (聊城大学环境与规划学院,聊城 252000)
}

\begin{abstract}
摘 要: 为了解城市湖泊不同水生植被区水体温室气体的溶存浓度及其影响因素, 于 2015 年 4-11 月按每月 2 次的频 率采用顶空平衡法对聊城市铃铛湖典型植被区一一菹草区、莲藕区和睡莲区表层水中 $\mathrm{CO}_{2} 、 \mathrm{CH}_{4}$ 和 $\mathrm{N}_{2} \mathrm{O}$ 的溶存浓度进行 监测, 计算水中温室气体的饱和度和排放通量, 并测定水温 $(\mathrm{T}) 、 \mathrm{pH}$ 、溶解氧 ( DO )、叶绿素 a 及营养盐浓度等理化指标, 以探究水体环境因子对温室气体溶存浓度的影响. 结果表明, 铃铛湖各植被区水体温室气体均处于过饱和状态, 是大气 温室气体的 “源”; 莲藕区 $\mathrm{CH}_{4}$ 浓度、饱和度和排放通量均显著高于菹草区, 而各植被区 $\mathrm{N}_{2} \mathrm{O}$ 和 $\mathrm{CO}_{2}$ 均无显著性差异; 不 同植被区湖水中 $\mathrm{DO}$ 、总氮 $(\mathrm{TN})$ 、总磷 $(\mathrm{TP})$ 和硝态氮 $\left(\mathrm{NO}_{3}^{-}-\mathrm{N}\right)$ 浓度具有显著差异, 其中 $\mathrm{DO} 、 \mathrm{TN}$ 和 $\mathrm{NO}_{3}^{-}-\mathrm{N}$ 浓度均表现为 菹草区最高, 莲藕区最低, 而 TP 浓度则正好相反; 各植被区温室气体浓度和水环境参数间的相关分析和多元回归分析 的结果表明, 水生植物可通过影响水体的理化性质对温室气体的产生和排放产生显著差异影响, 在菹草区亚硝态氮 $\left(\mathrm{NO}_{2}^{-}-\mathrm{N}\right) 、 \mathrm{NO}_{3}^{-}-\mathrm{N} 、 \mathrm{~T}$ 和 $\mathrm{DO}$ 是控制水体温室气体浓度的主要因子; 睡莲区为 $\mathrm{TP}$ 和 $\mathrm{pH}$; 莲藕区则为 $\mathrm{pH} 、 \mathrm{NO}_{2}^{-}-\mathrm{N}$ 和 $\mathrm{DO}$.
\end{abstract}

关键词: 温室气体;溶存浓度;影响因素;水生植被;城市湖泊;铃铛湖

\section{Dissolved greenhouse gas concentrations and the influencing factors in different vegetation zones of an urban lake}

DENG Huanguang, ZHANG Zhibo, LIU Tao, YIN Shanhong, DONG Jie, ZHANG Ju \& YAO Xin (School of Environment and Planning, Liaocheng University, Liaocheng 252000, P.R.China)

Abstract: Dissolved concentrations of carbon dioxide $\left(\mathrm{CO}_{2}\right)$, methane $\left(\mathrm{CH}_{4}\right)$ and nitrous oxide $\left(\mathrm{N}_{2} \mathrm{O}\right)$ in the surface water were measured using the headspace equilibrium method fortnightly from April to November of 2015 in the Potamogeton crispus zone, Nymhaea tetragona zone and Nelumbo nucifera zone of the Lake Lingdang in Liaocheng City. The saturations and emission fluxes of the greenhouse gases were calculated based on the two-layered diffusion model. Moreover, water temperature, $\mathrm{pH}$, dissolved oxygen (DO), chlorophyll-a and the nutrient concentrations in the water body were also measured in order to investigate their influences on the dissolved greenhouse gas concentrations. The results showed that the dissolved concentrations of greenhouse gases in different vegetation zones were all supersaturated, which indicated that Lake Lingdang was a source of atmospheric greenhouse gases. The concentrations, saturations and emission fluxes of $\mathrm{CH}_{4}$ in $N$. nucifera zone were significantly higher than those in $P$. crispus zone but no significant difference between the data of $\mathrm{N}_{2} \mathrm{O}$ and $\mathrm{CO}_{2}$ in different vegetation zones. The concentrations of DO, total nitrogen $(\mathrm{TN})$, total phosphorus $(\mathrm{TP})$ and nitrate $\left(\mathrm{NO}_{3}^{-}-\mathrm{N}\right)$ in three vegetation type zones also had significant differences. The average concentrations of DO, TN and $\mathrm{NO}_{3}^{-}-\mathrm{N}$ were highest in the P. crispus zone and lowest in the $N$. nucifera zone, but it was on the contrary for the average TP concentrations. The results of correlation analysis and multivariate regression analysis between the greenhouse gases and the water environment parameters suggested that the aquatic plants could affect the production and emission of greenhouse gases by influencing the physicochemical properties of water body. Greenhouse gas concentrations in lake water were mainly correlated to $\mathrm{NO}_{2}^{-}-\mathrm{N}, \mathrm{NO}_{3}^{-}-\mathrm{N}$, water temperature and $\mathrm{DO}$ in the $P$. crispus zone, while mainly correlated to $\mathrm{TP}$ and $\mathrm{pH}$ in the $N$. tetragona zone, and $\mathrm{pH}, \mathrm{NO}_{2}^{-}-\mathrm{N}$ and $\mathrm{DO}$ in the $N$. nucifera zone.

Keywords: Greenhouse gas; dissolved concentration; influencing factor; aquatic vegetation; urban lake; Lake Lingdang

* 国家自然科学基金项目 (41401563) 和山东省自然科学基金项目 (ZR2014JL028) 联合资助. 2018-08-31 收稿; 201812-01 收修改稿. 邓焕广 (1978 ), 男, 博士, 副教授;E-mail: lcdhg@ lcu.edu.cn. 
$\mathrm{CO}_{2} 、 \mathrm{CH}_{4}$ 和 $\mathrm{N}_{2} \mathrm{O}$ 是导致全球气候变暖的主要温室气体，对温室效应的贡献率分别为 $60 \% 、 15 \%$ 和 $5 \%{ }^{[1-2]}$. 内陆水体是温室气体重要的源和汇, 湖泊生态系统作为内陆水体的一部分, 虽然面积远小于海洋, 但因其位于内陆, 受人为影响较大, 与陆地生态系统的物质、能量、信息交换强烈, 且湖泊生态系统的生产 力较高 ${ }^{[3]}$, 因此也是温室气体的重要排放源 ${ }^{[2-3]}$. 水生植被是湖泊生态系统的重要组成部分, 具有多种生态 功能, 对水体的 $\mathrm{C} 、 \mathrm{~N}$ 循环过程起着重要调节作用. 不同类型的水生植物通过自身特性影响、改变所处水体 环境的物理和化学条件, 从而形成与其相辅相成的生物学环境条件, 与水体中的微生物进行复杂的交互作 用, 最终影响发生在水体和底泥中的各种生化反应过程, 从而影响水体温室气体的产生和排放 ${ }^{[4-5]}$.

城市湖泊多属于静止或缓流水体，由于地理位置的特殊性，相对封闭，交换能力差，底泥较厚且有机 质和 N、P 等营养物质丰富, 常处于富营养状态 ${ }^{[6]}$. 陆源有机物的大量输人及其在底泥中的储存会刺激水生 生物和微生物的新陈代谢, 由此导致温室气体的大量产生和排放 ${ }^{[2]}$. 近年来, 对富营养化水体具有较强适 应能力和净化作用的沉水植物一淔草逐渐成为城市湖泊水生植物的优势种 ${ }^{[7]}$; 而另一方面, 为了景观需要, 城市湖泊中往往会种植观赏性水生植物如睡莲 (浮水植物)、荷花 (挺水植物) 等. 已有研究较多关注湖泊温 室气体的源汇效应及环境参数 (气温、气压、太阳辐射、日照时数、风速等) 和水体环境因子 ( $\mathrm{pH} 、 \mathrm{DO}$ 、盐度、营 养盐水平等) 对温室气体排放的影响 ${ }^{[8-10]}$, 未考虑不同水生植被的影响; 而部分已有关于水生植被对温室气 体排放影响的研究多基于实验室模拟 ${ }^{[5,11-12]}$ 或短期监测 ${ }^{[4,13]}$, 缺乏长期现场监测的研究结果. 当前对湖泊温 室气体排放通量的研究除静态箱观测法外, 顶空平衡法也是较为常用的方法之一 ${ }^{[8,10]}$. 本研究选择位于山 东省聊城市市区的铃铛湖，于 2015 年 4-11 月 (非冰封期) 采用顶空平衡法对铃铛湖不同植被区水体中温 室气体的溶存浓度及水质指标进行了监测分析, 比较了不同植被区水体中温室气体浓度、饱和度和排放通 量的差异, 探讨了影响水体中温室气体溶存浓度的因素, 研究结果为深人理解城市湖泊温室气体浓度的时 空变化特征及其与环境因素之间的相互关系, 准确评估城市湖泊中植被的选择对大气中温室气体的影响提 供了科学数据支撑和理论参考.

\section{1 材料与方法}

\section{1 采样区域概况}

聊城市位于温带季风气候区, 四季分明, 属半干早大陆性气候. 聊城市有 “江北水城”之称, 仅市区水 域面积就多达 $13 \mathrm{~km}^{2}$. 铃铛湖属于聊城市城区河湖水系, 位于京杭古运河河畔, 是典型的城市景观水体. 铃 铛湖东西约 $1 \mathrm{~km}$, 西接东昌湖, 东通京杭古运河, 水面约 $10 \mathrm{hm}^{2}$, 平均水深 $2 \mathrm{~m}$, 水面开敞广阔, 主要植被 有菹草 (Potamogeton crispus)、睡莲 (Nymhaea tetragona) 和莲藕 (Nelumbo nucifera), 在岸边零星分布有少量 的芦苇和香蒲; 因此按主要植被类型的不同, 将水域分为菹草区、睡莲区和莲藕区, 并在各区植被生长较为 均一的水域各设置 1 个采样点 (图 1), 该采样点避开了有芦苇和香蒲生长的水域且离岸带有一定距离, 因 此芦苇和香蒲对各植被区水体环境的影响可忽略不计.

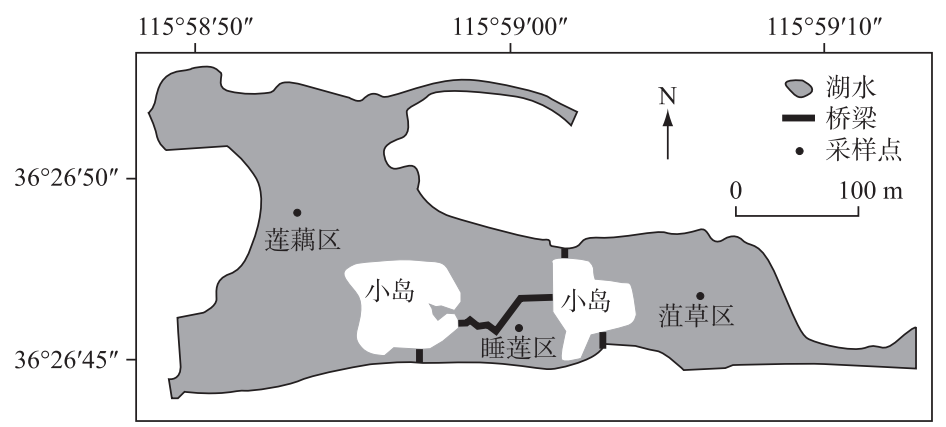

图 1 铃铛湖植被分布和采样点示意

Fig.1 Sketch of Lake Lingdang showing the vegetation zones and sampling sites 


\section{2 样品采集与分析}

于 2015 年 4- 11 月按每月 2 次的频率分别在铃铛湖的渵草区、睡莲区和莲藕区定点采集水样、水中气 体和空气样品 (由于 8 月份处于雨季受降雨影响, 水体波动较大, 故未进行采样), 每次样品的采集时间均 为采样当天下午 3:00. 使用注射器采集现场空气 ( 3 个平行样) 于气体采样袋中; 采用卡盖式采水器采集水 面下 $20 \mathrm{~cm}$ 处水样, 将水样注人 $100 \mathrm{ml}$ 两头具有密封硅胶垫和密封螺帽的有机玻璃管内, 并使其溢出 $2 / 3$ 管体积的水样后密封, 并注人 $0.2 \mathrm{ml}$ 饱和 $\mathrm{HgCl}_{2}$ 溶液以抑制微生物活性, 每个样点取 3 个平行样用于测定 水中 $\mathrm{N}_{2} \mathrm{O} 、 \mathrm{CH}_{4}$ 的溶存浓度; 同时按相同步骤再采集 3 个平行样但不加饱和 $\mathrm{HgCl}_{2}$ 用于测定水中溶存的 $\mathrm{CO}_{2}$ 浓度. 每次采样都要重新迅速采集湖水, 以降低水体中温室气体在采集样品时向大气扩散导致的误差. 回 实验室后立即采用顶空平衡法 ${ }^{[14]}$ (水气比 $1: 1$ ) 测定温室气体浓度, 即用注射器从一端注人 $50 \mathrm{ml}$ 高纯氮 气, 并利用重力从另一端扎入的注射器针头排出相同体积的水样, 振荡 $10 \mathrm{~min}$ 静置 $1 \mathrm{~h}$ 后抽取顶空气体测 定温室气体浓度; 另取部分水样置于聚乙烯塑料瓶中, 用于水体 $N 、 P 、$ 叶绿素 a 等理化指标的测定, 每次采 集 3 个平行样; 同时在现场使用 HI9145 型溶解氧仪 (意大利 HANNA 公司) 测定并记录水体水温 ( T) 和溶解 氧 (DO) 浓度; 水体冰封会影响水一气界面交换造成水体中气体的累积, 因此在冰封期 (12 月至次年 3 月) 不进行样品采集.

气体样品采用 Agilent 7890A 型气相色谱仪 (美国 Agilent 公司) 测定 $\mathrm{N}_{2} \mathrm{O} 、 \mathrm{CO}_{2}$ 和 $\mathrm{CH}_{4}$. 水样 $\mathrm{pH}$ 值采用 IQ150 型 $\mathrm{pH}$ 计测定. 取 $100 \mathrm{ml}$ 水样过 $0.45 \mu \mathrm{m}$ 滤膜用以测定硝态氮 $\left(\mathrm{NO}_{3}^{-}-\mathrm{N}\right)$ 、亚硝态氮 $\left(\mathrm{NO}_{2}^{-}-\mathrm{N}\right)$ 、铵态氮 $\left(\mathrm{NH}_{4}^{+}-\mathrm{N}\right)$ 和可溶性正磷酸盐( DIP) 浓度, 滤膜采用 $90 \%$ 丙酮提取后分光光度法测定叶绿素 a (Chl.a) 浓度; 另取未过滤水样测定总氮 ( TN ) 和总磷 (TP) 浓度. $\mathrm{NH}_{4}^{+}-\mathrm{N}$ 、 $\mathrm{DIP}$ 和 $\mathrm{NO}_{2}^{-}-\mathrm{N}$ 浓度分别采用纳氏试剂分光光度 法、钼锑抗分光光度法和 $\mathrm{N}$-( 1-荎基) -乙二胺光度法测定; $\mathrm{NO}_{3}^{-}-\mathrm{N}$ 浓度采用紫外分光光度法测定; $\mathrm{TN}$ 浓度采 用过硫酸钾氧化一紫外分光光度法测定; TP 浓度采用过硫酸钾氧化一锄锑抗分光光度法测定 ${ }^{[15]}$.

\section{3 数据处理与统计}

水样中温室气体溶存浓度 $\left(C_{\mathrm{W}}, \mu \mathrm{mol} / \mathrm{L}\right)$ 的计算公式为 ${ }^{[16]}$ :

$$
C_{\mathrm{W}}=\left[\left(C_{\mathrm{Al}}-C_{\mathrm{A}}\right) V_{\mathrm{Al}}+\alpha \cdot C_{\mathrm{Al}} \cdot V_{\mathrm{W}}\right] / V_{\mathrm{W}}
$$

式中, $C_{\mathrm{Al}}$ 为培养管中水一气交换达到平衡时顶空气体样品中温室气体的浓度 $\left(\mu \mathrm{mol} / \mathrm{L}\right.$ 或 $\left.10^{-6} \mathrm{~V} / \mathrm{V}\right) ; C_{\mathrm{A}}$ 为 采样点大气中温室气体的浓度 $(\mu \mathrm{mol} / \mathrm{L}) ; V_{\mathrm{Al}}$ 为培养管中顶空空气体积 $(\mathrm{L}) ; V_{\mathrm{W}}$ 为培养管中水样的体积 $(\mathrm{L})$; $\alpha$ 为布氏系数 (Bunsen coefficient, $\mathrm{mol} / \mathrm{L}$ ).

水体温室气体溶解饱和度 $(S, \%)$ 是实测的采样点 $C_{\mathrm{W}}$ 与采样点现场条件下水体温室气体饱和浓度 $\left(C_{\mathrm{Ws}}, \mu \mathrm{mol} / \mathrm{L}\right)$ 的比值, 计算公式为 ${ }^{[16]}$ :

$$
\begin{gathered}
S=C_{\mathrm{W}} / C_{\mathrm{Ws}_{\mathrm{s}}} \\
C_{\mathrm{W}_{\mathrm{s}}}=\alpha \cdot C_{\mathrm{A}}
\end{gathered}
$$

双层模型被广泛应用于气体在水一气界面交换速率的定量计算 ${ }^{[17]}$, 铃铛湖水面开阔, 流速极其缓慢 (几乎静止), 满足双层模型的假定条件 ${ }^{[16-17]}$, 因此采用双层模型计算铃铛湖水一气界面温室气体的排放通 量 $(F)$, 计算公式为 ${ }^{[14,16]}$ :

$$
F=k \cdot \Delta C
$$

式中, $\Delta C$ 为水一气界面温室气体浓度的差值, $\Delta C=C_{\mathrm{W}}-C_{\mathrm{A}} ; k$ 为扩散系数, 计算公式为 ${ }^{[14]}: k=1.91 \mathrm{e}^{0.35 \mu}(S c /$ $600)^{-1 / 2}, \mu$ 为 $10 \mathrm{~m}$ 处风速 $(\mathrm{m} / \mathrm{s})$, 在本研究中风速数据来源于聊城大学地理园的气象自动监测站; $S c$ 为施 密特数 (Schmidt number), 为水的运动黏度 $(v)$ 与气体分子扩散系数 $(D)$ 之比.

数据的统计分析采用软件 Excel 2013 和 SPSS 18.5 完成, 不同植被区水环境参数和温室气体排放浓度、 饱和度和排放通量间的差异采用单因素方差分析 (One-way ANOVA) 在 0.05 的显著性水平上进行检验，图 形采用软件 Origin 2015 绘制.

\section{2 结果和讨论}

\section{1 铃铛湖水环境参数和水质状况}

铃铛湖 4-11 月全湖的 $\mathrm{pH} 、 \mathrm{DO} 、 \mathrm{TP}$ 和 $\mathrm{NH}_{4}^{+}-\mathrm{N}$ 的平均浓度均能达到《地表水环境质量标准》( GB $3838-$ 
2002) V 类水标准要求, 能满足一般景观用水要求 (表 1 ). 不同植被类型水体中 $\mathrm{T} 、 \mathrm{pH} 、 \mathrm{NO}_{2}^{-}-\mathrm{N} 、 \mathrm{NH}_{4}^{+}-\mathrm{N} 、 \mathrm{DIP}$ 和 Chl.a 平均浓度无显著性差异 $(P>0.05)$, 而 DO、TN、TP 和 $\mathrm{NO}_{3}^{-}-\mathrm{N}$ 平均浓度具有显著差异 $(P<0.05)$, 其 中 $\mathrm{DO} 、 \mathrm{TN}$ 和 $\mathrm{NO}_{3}^{-}-\mathrm{N}$ 均表现为菹草区浓度最高, 莲藕区浓度最低, 而 $\mathrm{TP}$ 浓度则正好相反, 表现为莲藕区水 中 $\mathrm{TP}$ 浓度最高, 而菹草区最低. 菹草为沉水植物, 在生长期其光合作用可吸收利用 $\mathrm{CO}_{2}$, 并生成 $\mathrm{O}_{2}$, 使水 中 DO 浓度增加, 有利于 $N$ 的硝化作用, 同时菹草对水中磷具有较好的净化作用 ${ }^{[18]}$; 而睡莲和莲藕分别为 浮水植物和挺水植物, 在生长期其叶面覆盖遮挡水面, 阻碍了大气复氧并影响了水中藻类的光合作用, 导 致水中 DO 浓度降低.

\section{表 1 铃铛湖水环境参数 *}

Tab. 1 The water environment parameters of Lake Lingdang

\begin{tabular}{|c|c|c|c|c|c|c|c|c|c|c|}
\hline & $\mathrm{T} /{ }^{\circ} \mathrm{C}$ & $\mathrm{pH}$ & $\begin{array}{c}\mathrm{D} 0 / \\
(\mathrm{mg} / \mathrm{L})\end{array}$ & $\begin{array}{c}\mathrm{TN} / \\
(\mathrm{mg} / \mathrm{L})\end{array}$ & $\begin{array}{c}\mathrm{TP} / \\
(\mathrm{mg} / \mathrm{L})\end{array}$ & $\begin{array}{l}\mathrm{NO}_{3}^{-}-\mathrm{N} / \\
(\mathrm{mg} / \mathrm{L})\end{array}$ & $\begin{array}{l}\mathrm{NO}_{2}^{-}-\mathrm{N} / \\
(\mathrm{mg} / \mathrm{L})\end{array}$ & $\begin{array}{l}\mathrm{NH}_{4}^{+}-\mathrm{N} / \\
(\mathrm{mg} / \mathrm{L})\end{array}$ & $\begin{array}{c}\mathrm{DIP} / \\
(\mathrm{mg} / \mathrm{L})\end{array}$ & $\begin{array}{l}\text { Chl.a/ } \\
(\mu \mathrm{g} / \mathrm{L})\end{array}$ \\
\hline 菹草区 & $23.4 \pm 6.66^{\mathrm{a}}$ & $8.87 \pm 0.22^{\mathrm{a}}$ & $9.35 \pm 1.37^{\mathrm{a}}$ & $2.77 \pm 1.27^{\mathrm{a}}$ & $0.092 \pm 0.038^{\mathrm{a}}$ & $1.43 \pm 1.31^{\mathrm{a}}$ & $0.029 \pm 0.018^{\mathrm{a}}$ & $0.183 \pm 0.069^{\mathrm{a}}$ & $0.019 \pm 0.014^{\mathrm{a}}$ & $33.2 \pm 24.6^{\mathrm{a}}$ \\
\hline 睡莲区 & $23.3 \pm 6.61^{\mathrm{a}}$ & $8.71 \pm 0.22^{\mathrm{a}}$ & $7.82 \pm 1.81^{\mathrm{b}}$ & $2.08 \pm 0.62^{\mathrm{ac}}$ & $0.120 \pm 0.042^{b}$ & $0.73 \pm 0.91^{\mathrm{ac}}$ & $0.023 \pm 0.013^{\mathrm{a}}$ & $0.246 \pm 0.123^{\mathrm{a}}$ & $0.018 \pm 0.016^{\mathrm{a}}$ & $38.3 \pm 22.4^{\mathrm{a}}$ \\
\hline 莲藕区 & $23.3 \pm 6.44^{\mathrm{a}}$ & $8.75 \pm 0.35^{\mathrm{a}}$ & $7.54 \pm 2.33^{b}$ & $1.88 \pm 0.35^{\text {bc }}$ & $0.135 \pm 0.033^{\mathrm{b}}$ & $0.43 \pm 0.35^{\text {bc }}$ & $0.021 \pm 0.013^{\mathrm{a}}$ & $0.239 \pm 0.135^{\mathrm{a}}$ & $0.020 \pm 0.014^{\mathrm{a}}$ & $37.7 \pm 24.3^{\mathrm{a}}$ \\
\hline 全湖 & $23.3 \pm 6.43$ & $8.78 \pm 0.27$ & $8.24 \pm 2.01$ & $2.24 \pm 0.91$ & $0.116 \pm 0.041$ & $0.87 \pm 1.02$ & $0.024 \pm 0.015$ & $0.222 \pm 0.114$ & $0.019 \pm 0.015$ & $36.4 \pm 23.4$ \\
\hline $\begin{array}{c}\text { GB 3838-2002 } \\
\text { V类水标准 }\end{array}$ & - & $6 \sim 9$ & $\geqslant 2$ & $\leqslant 2.0$ & $\leqslant 0.2$ & - & - & $\leqslant 2$ & - & - \\
\hline
\end{tabular}

* 同列不同小写字母表示具有显著差异 $(P<0.05)$, 相同字母表示无显著性差异 $(P>0.05)$.

\section{2 铃铛湖温室气体浓度、饱和度和排放通量}

如表 2 所示, 铃铛湖水体中 $\mathrm{N}_{2} \mathrm{O} 、 \mathrm{CH}_{4}$ 和 $\mathrm{CO}_{2}$ 的浓度分别为 $41.4 \pm 15.2 \mathrm{nmol} / \mathrm{L} 、 0.608 \pm 0.757 \mu \mathrm{mol} / \mathrm{L}$ 和 $34.7 \pm 11.7 \mu \mathrm{mol} / \mathrm{L}$, 低于太湖夏季蓝藻水华堆积区表层水体中 $\mathrm{N}_{2} \mathrm{O}$ 和 $\mathrm{CH}_{4}$ 的溶存浓度 $(0.054 \pm 0.024$ 和 $2.33 \pm$ $1.46 \mu \mathrm{mol} / \mathrm{L})$, 但高于开阔湖区的浓度 $(0.023 \pm 0.012 \text { 和 } 0.14 \pm 0.059 \mu \mathrm{mol} / \mathrm{L})^{[10]}$. 饱和度分别为 $304 \% \pm$ $111 \% 、 21875 \% \pm 26998 \%$ 和 $235 \% \pm 68 \%$, 均处于高度过饱和状态，其中 $\mathrm{CH}_{4}$ 饱和度范围为 $2868 \% \sim 157660 \%$, 远高于 $\mathrm{N}_{2} \mathrm{O}$ 和 $\mathrm{CO}_{2}$; 排放通量分别为 $0.027 \pm 0.015 、 0.253 \pm 0.354$ 和 $7.94 \pm 4.32 \mathrm{mg} /\left(\mathrm{m}^{2} \cdot \mathrm{h}\right)$, 均表现为大气中 温室气体的“源”. 温志丹等 ${ }^{[8]}$ 也发现长春市城市内湖主要表现为大气中 $\mathrm{CO}_{2}$ 和 $\mathrm{CH}_{4}$ 的 “源”. 不同植被区水 体中 $\mathrm{CH}_{4}$ 浓度、饱和度和排放通量有显著性差异, 表现为莲藕区 $\mathrm{CH}_{4}$ 浓度、饱和度和排放通量均显著高于菹 草区 $(P<0.05)$, 但睡莲区和莲藕区间无显著差异 $(P>0.05)$; 各植被区 $\mathrm{N}_{2} \mathrm{O}$ 和 $\mathrm{CO}_{2}$ 浓度、饱和度和排放通量 均无显著性差异 $(P>0.05)$.

表 2 铃铛湖不同植被区水体温室气体溶存浓度、饱和度和排放通量的参数统计 *

Tab.2 The parameter statistics of concentrations, saturation and fluxes of greenhouse gases in the different vegetation type zones of Lake Lingdang

\begin{tabular}{|c|c|c|c|c|c|c|c|c|c|c|}
\hline \multirow{2}{*}{$\begin{array}{l}\text { 植被 } \\
\text { 类型 }\end{array}$} & \multirow{2}{*}{ 参数 } & \multicolumn{3}{|c|}{$\mathrm{N}_{2} \mathrm{O}$} & \multicolumn{3}{|c|}{$\mathrm{CH}_{4}$} & \multicolumn{3}{|c|}{$\mathrm{CO}_{2}$} \\
\hline & & 浓度 & 饱和度 & 排放通量 & 浓度 & 饱和度 & 排放通量 & 浓度 & 饱和度 & 排放通量 \\
\hline \multirow[t]{2}{*}{ 菹草区 } & 平均值 & $39.8 \pm 14.5^{\mathrm{a}}$ & $290 \pm 73^{\mathrm{a}}$ & $0.025 \pm 0.013^{\mathrm{a}}$ & $0.229 \pm 0.074^{\mathrm{a}}$ & $8157 \pm 2633^{\mathrm{a}}$ & $0.092 \pm 0.038^{\mathrm{a}}$ & $31.3 \pm 8.4^{\mathrm{a}}$ & $215 \pm 64^{\mathrm{a}}$ & $6.55 \pm 3.24^{\mathrm{a}}$ \\
\hline & 范围 & $20.3 \sim 65.2$ & $222 \sim 474$ & $0.007 \sim 0.048$ & $0.092 \sim 0.384$ & $2868 \sim 13268$ & $0.024 \sim 0.177$ & $21.4 \sim 50.0$ & $147 \sim 406$ & $3.29 \sim 16.13$ \\
\hline \multirow[t]{2}{*}{ 睡莲区 } & 平均值 & $42.2 \pm 16.3^{\mathrm{a}}$ & $316 \pm 153^{a}$ & $0.028 \pm 0.017^{\mathrm{a}}$ & $1.005 \pm 1.198^{\mathrm{ab}}$ & $36208 \pm 42480^{\mathrm{ab}}$ & $0.430 \pm 0.568^{\mathrm{ab}}$ & $35.4 \pm 10.5^{\mathrm{a}}$ & $243 \pm 74^{a}$ & $8.37 \pm 4.70^{\mathrm{a}}$ \\
\hline & 范围 & $20.9 \sim 62.6$ & $217 \sim 807$ & $0.009 \sim 0.062$ & $0.276 \sim 4.562$ & $8784 \sim 157660$ & $0.075 \sim 2.122$ & $26.4 \sim 60.9$ & $182 \sim 469$ & $3.99 \sim 22.88$ \\
\hline \multirow[t]{2}{*}{ 莲藕区 } & 平均值 & $42.0 \pm 16.0^{\mathrm{a}}$ & $308 \pm 100^{\mathrm{a}}$ & $0.028 \pm 0.015^{\mathrm{a}}$ & $0.591 \pm 0.218^{b}$ & $21261 \pm 8362^{\mathrm{b}}$ & $0.237 \pm 0.106^{b}$ & $37.4 \pm 15.3^{\mathrm{a}}$ & $247 \pm 67^{\mathrm{a}}$ & $8.90 \pm 4.83^{\mathrm{a}}$ \\
\hline & 范围 & $22.7 \sim 69.3$ & $231 \sim 606$ & $0.009 \sim 0.053$ & $0.317 \sim 1.090$ & $10152 \sim 37676$ & $0.087 \sim 0.506$ & $20.7 \sim 66.5$ & $158 \sim 416$ & $2.78 \sim 19.55$ \\
\hline \multirow[t]{2}{*}{ 全湖 } & 平均值 & $41.4 \pm 15.2$ & $304 \pm 111$ & $0.027 \pm 0.015$ & $0.608 \pm 0.757$ & $21875 \pm 26998$ & $0.253 \pm 0.354$ & $34.7 \pm 11.7$ & $235 \pm 68$ & $7.94 \pm 4.32$ \\
\hline & 范围 & $20.3 \sim 69.3$ & $217 \sim 807$ & $0.007 \sim 0.062$ & $0.092 \sim 4.562$ & $2868 \sim 157660$ & $0.024 \sim 2.122$ & $20.7 \sim 66.5$ & $147 \sim 469$ & $2.78 \sim 22.88$ \\
\hline
\end{tabular}

* 饱和度单位为 $\%$; 排放通量单位为 $\mathrm{mg} /\left(\mathrm{m}^{2} \cdot \mathrm{h}\right) ; \mathrm{CO}_{2}$ 和 $\mathrm{CH}_{4}$ 浓度单位为 $\mu \mathrm{mol} / \mathrm{L}, \mathrm{N}_{2} \mathrm{O}$ 浓度单位为 $\mathrm{nmol} / \mathrm{L}$. 同一列不同 小写字母表示具有显著性差异 $(P<0.05)$, 相同字母表示无显著性差异 $(P>0.05)$. 
不同植被区水体各温室气体浓度、饱和度和排放通量随时间具有较为一致的变化规律 (图 2). 各植被 区水体中 $\mathrm{N}_{2} \mathrm{O}$ 浓度和排放通量随着时间变化出现显著降低趋势, 11 月水体中 $\mathrm{N}_{2} \mathrm{O}$ 浓度和排放通量分别比 4 月平均下降了 $60 \%$ 和 $76 \% ; \mathrm{N}_{2} \mathrm{O}$ 饱和度亦有所降低, 下降幅度约为 $28 \%$, 但仍处于过饱和状态. 各植被区 $\mathrm{CH}_{4}$ 总体表现为中间高两端低的变化趋势, 其浓度的最大值均出现在第 91 天 (7 月 9 日), 睡莲区水体中 $\mathrm{CH}_{4}$ 浓度在第 91 天和第 57 天 (6 月 5 日) 的峰值分别为 2.40 和 $4.56 \mu \mathrm{mol} / \mathrm{L}$, 均显著高于其他月份以及菹草 区和睡莲区 $\mathrm{CH}_{4}$ 浓度. 各植被区水体中 $\mathrm{CO}_{2}$ 浓度总体表现为随时间先降低后上升的反复波动变化. 菹草区 水体中 $\mathrm{CO}_{2}$ 浓度的峰值出现在 4 月 $(50.0 \mu \mathrm{mol} / \mathrm{L})$, 睡莲区出现在 7 月 $(60.9 \mu \mathrm{mol} / \mathrm{L})$, 莲藕区则在 11 月水 中 $\mathrm{CO}_{2}$ 浓度最高 $(66.5 \mu \mathrm{mol} / \mathrm{L})$.
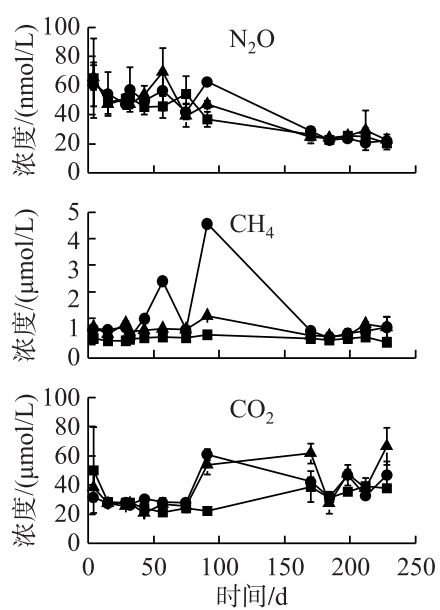
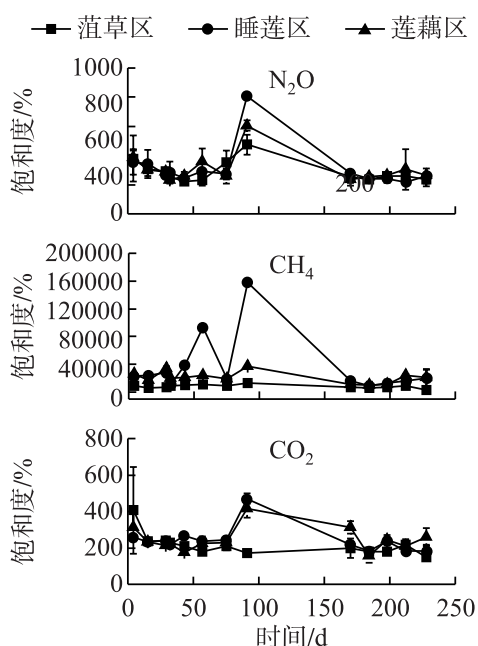

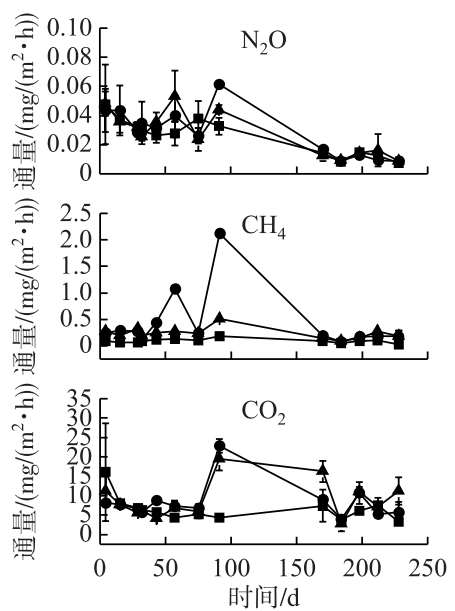

图 2 铃铛湖不同植被区水体温室气体浓度、饱和度和排放通量

(误差线为 3 个平行样间的标准偏差)

Fig. 2 The concentration, saturation and flux of greenhouse gases in the different vegetation type zones of Lake Lingdang

由于样品的采集均是在同一湖泊进行, 因此, 气温、风速、气压等环境因素均相同, 植被类型的不同及 其水体环境参数之间的差异可能是造成不同植被区温室气体浓度差异的主要原因. 一方面是在植物生长 期, 淔草、睡莲和莲藕分别作为沉水植物、浮水植物和挺水植物对水体理化性质和水质产生不同的影响; 另 一方面是在植物衰亡期, 与睡莲和莲藕不同, 菹草秋季发芽, 冬春季生长, 夏季开始时衰亡腐烂; 因此, 菹 草在衰亡后其残体往往被公园管理处组织打捞出湖, 避免了菹草衰亡过程中碳氮等营养物质向水体的释 放 ${ }^{[19-20]}$, 进而使其在 6 月初的腐烂期水体温室气体浓度降低; 在秋季睡莲和莲藕衰亡后则未清理, 其残体 进人水体后在来年春季腐烂分解消耗水中 DO 并释放 $\mathrm{N} 、 \mathrm{P}$ 等营养物质, 促进反硝化作用和 $\mathrm{N}_{2} \mathrm{O}$ 的产生排 放, 沉积在湖泊底泥中的有机残体在厌氧条件下分解产生 $\mathrm{CH}_{4}$ 释放进人水体和大气, 从而导致睡莲区和莲 藕区湖水中温室气体浓度高于菹草区.

\section{3 环境因子对铃铛湖温室气体溶存浓度的影响}

研究表明 ${ }^{[4,13]}$ 水体理化性质是影响水体温室气体产生的重要因素, 因此为进一步分析水质因子对湖水 中温室气体溶存浓度的影响, 采用相关分析和多元回归分析对其进行了分析. 如表 3 所示, 菹草区水中温 室气体的浓度与 $\mathrm{T} 、 \mathrm{TP} 、 \mathrm{NO}_{3}^{-}-\mathrm{N}$ 和 $\mathrm{NO}_{2}^{-}-\mathrm{N}$ 均具有显著相关性, 睡莲区与温室气体浓度具有显著相关性的水 质指标有 $\mathrm{pH} 、 \mathrm{~T} 、 \mathrm{TP} 、 \mathrm{NO}_{2}^{-}-\mathrm{N}$ 和 Chl. a, 而莲藕区为 $\mathrm{DO} 、 \mathrm{pH} 、 \mathrm{TN} 、 \mathrm{TP} 、 \mathrm{NO}_{2}^{-}-\mathrm{N}$ 和 Chl.a. $\mathrm{TP}$ 和 $\mathrm{NO}_{2}^{-}-\mathrm{N}$ 是 3 种植被 区共有的相关因子, 但是在不同植被区其与各温室气体间的相关关系和相关程度各有差异, 各植被区 TP 与 $\mathrm{N}_{2} \mathrm{O} 、 \mathrm{CH}_{4}$ 浓度均呈正相关, 而与 $\mathrm{CO}_{2}$ 浓度呈负相关; $\mathrm{NO}_{2}^{-}-\mathrm{N}$ 与 $\mathrm{N}_{2} \mathrm{O}$ 浓度呈正相关, 且还与莲藕区 $\mathrm{CH}_{4}$ 呈 显著正相关. 各植被区水中温室气体浓度与 $\mathrm{NH}_{4}^{+}-\mathrm{N}$ 和 $\mathrm{DIP}$ 均无显著相关性, 这可能与 $\mathrm{NH}_{4}^{+}-\mathrm{N}$ 和 $\mathrm{DIP}$ 浓度 
在各植被区均在同一浓度水平以及 DIP 浓度较低有关(表 1 ).

表 3 铃铛湖不同植被区水体中温室气体浓度与水质参数间的 Pearson 相关系数 $(n=13)$

Tab.3 The Pearson correlation coefficients between the greenhouse gas concentrations and the water quality parameters in different vegetation type zones of Lake Lingdang

\begin{tabular}{|c|c|c|c|c|c|c|c|c|c|}
\hline \multirow{2}{*}{$\begin{array}{l}\text { 水质 } \\
\text { 参数 }\end{array}$} & \multicolumn{3}{|c|}{ 菹草区 } & \multicolumn{3}{|c|}{ 睡莲区 } & \multicolumn{3}{|c|}{ 莲藕区 } \\
\hline & $\mathrm{N}_{2} \mathrm{O}$ 浓度 & $\mathrm{CH}_{4}$ 浓度 & $\mathrm{CO}_{2}$ 浓度 & $\mathrm{N}_{2} \mathrm{O}$ 浓度 & $\mathrm{CH}_{4}$ 浓度 & $\mathrm{CO}_{2}$ 浓度 & $\mathrm{N}_{2} \mathrm{O}$ 浓度 & $\mathrm{CH}_{4}$ 浓度 & $\mathrm{CO}_{2}$ 浓度 \\
\hline DO & -0.12 & 0.38 & -0.11 & -0.25 & -0.54 & -0.37 & 0.54 & -0.14 & $-0.77^{\mathrm{a}}$ \\
\hline $\mathrm{pH}$ & 0.29 & 0.40 & -0.27 & -0.27 & $-0.75^{\mathrm{a}}$ & $-0.60^{\mathrm{b}}$ & $0.68^{\mathrm{b}}$ & 0.16 & $-0.69^{b}$ \\
\hline $\mathrm{T}$ & 0.37 & $0.61^{\mathrm{b}}$ & $-0.77^{\mathrm{a}}$ & $0.58^{\mathrm{b}}$ & $0.57^{\mathrm{b}}$ & -0.03 & 0.45 & 0.12 & -0.41 \\
\hline $\mathrm{TN}$ & 0.33 & -0.55 & -0.11 & 0.09 & 0.16 & 0.26 & 0.05 & $0.58^{\mathrm{b}}$ & 0.16 \\
\hline TP & 0.44 & $0.56^{\mathrm{b}}$ & -0.49 & $0.58^{\mathrm{b}}$ & 0.51 & -0.18 & $0.61^{\mathrm{b}}$ & 0.30 & $-0.62^{\mathrm{b}}$ \\
\hline $\mathrm{NH}_{4}^{+}-\mathrm{N}$ & 0.31 & -0.40 & 0.05 & -0.27 & 0.06 & 0.36 & -0.12 & 0.18 & 0.52 \\
\hline $\mathrm{NO}_{3}^{-}-\mathrm{N}$ & 0.38 & $-0.61^{b}$ & 0.08 & 0.07 & -0.13 & 0.11 & 0.27 & 0.42 & 0.17 \\
\hline $\mathrm{NO}_{2}^{-}-\mathrm{N}$ & $0.78^{\mathrm{a}}$ & -0.12 & -0.40 & $0.57^{\mathrm{b}}$ & 0.03 & -0.15 & 0.25 & $0.62^{\mathrm{b}}$ & 0.04 \\
\hline DIP & -0.34 & -0.13 & 0.37 & -0.31 & -0.36 & -0.23 & -0.16 & -0.46 & -0.30 \\
\hline Chl.a & -0.55 & 0.48 & -0.07 & -0.04 & $0.57^{\mathrm{b}}$ & 0.43 & $-0.59^{\mathrm{b}}$ & -0.25 & 0.12 \\
\hline
\end{tabular}

a 表示 $99 \%$ 置信区间显著; b 表示 $95 \%$ 置信区间显著.

如表 4 所示, 不同植被区各温室气体浓度多与 1 2 个水质指标间构建成立具有统计学意义的线性回 归方程. 不同植被区同一种温室气体的影响因子各不相同, $\mathrm{NO}_{2}$ 在蕰草区主要受到 $\mathrm{NO}_{2}^{-}-\mathrm{N}$ 和 $\mathrm{NO}_{3}^{-}-\mathrm{N}$ 的影 响, 在睡莲区为 $\mathrm{TP}$, 而在莲藕区则为 $\mathrm{pH} ; \mathrm{CH}_{4}$ 在蕰草区为 $\mathrm{T}$ 和 $\mathrm{NO}_{3}^{-}-\mathrm{N}$, 在睡莲区为 $\mathrm{pH}$, 而在莲藕区为 $\mathrm{NO}_{2}^{-}-\mathrm{N} ; \mathrm{CO}_{2}$ 在蕰草区为 $\mathrm{T}$ 和 $\mathrm{DO}$, 在睡莲区为 $\mathrm{pH}$ 和 $\mathrm{TP}$, 在莲藕区则为 DO. 总的来说, 蕰草区湖水中温室气 体浓度主要与 $\mathrm{NO}_{2}^{-}-\mathrm{N} 、 \mathrm{NO}_{3}^{-}-\mathrm{N}$ 、T 和 $\mathrm{DO}$ 有关; 睡莲区为 $\mathrm{TP}$ 和 $\mathrm{pH}$; 莲藕区为 $\mathrm{pH} 、 \mathrm{NO}_{2}^{-}-\mathrm{N}$ 和 DO.

在蕰草区, 一方面, 当气温升高, 水温也随之升高, 菹草光合作用增强, 降低水中 $\mathrm{CO}_{2}$ 浓度; 另一方面, 气体在水中的溶解度与温度呈反比, 当温度升高, 有利于 $\mathrm{CO}_{2}$ 从水中释放进人大气, 两方面的共同作用导 致 $\mathrm{CO}_{2}$ 浓度与水温呈显著负相关. 水体中 $\mathrm{CH}_{4}$ 主要来源于沉积物的厌氧降解 ${ }^{[21]}$, 当水温升高时有利于有机 物的矿化, 使产甲烷速率增强 ${ }^{[22]} \cdot \mathrm{NO}_{3}^{-}-\mathrm{N}$ 浓度是影响䓚草区 $\mathrm{CH}_{4}$ 溶存浓度的主要因子 (表 4), 且与其呈显 著负相关 (表 3). $\mathrm{NO}_{2}^{-}$为硝化和反硝化过程的中间产物, 其产生取决于水体 $\mathrm{N}$ 的转化速率及环境条件, 而 $\mathrm{N}_{2} \mathrm{O}$ 主要源自硝化和反硝化微生物的脱氮反应过程 ${ }^{[5]}$, 由于铃铛湖上覆水中 DO 浓度较高 (表 1 ), 使得 $\mathrm{NO}_{3}^{-}$和 $\mathrm{NO}_{2}^{-}$还原受阻, 反硝化作用受到抑制, 因此, $\mathrm{N}_{2} \mathrm{O}$ 浓度与水中 $\mathrm{NO}_{2}^{-}-\mathrm{N}$ 浓度具有显著正相关关系. 总体 来说, 蕰草区温室气体溶存浓度主要受到 $\mathrm{NO}_{2}^{-}-\mathrm{N} 、 \mathrm{NO}_{3}^{-}-\mathrm{N}$ 和 $\mathrm{DO}$ 等因子的影响, 这可能与其较高的 DO 和氮 浓度有关(表 1 ).

表 4 铃铛湖不同植被区水体中温室气体浓度与水质参数间线性回归方程

Tab.4 The linear regression equations between the dissolved greenhouse gas concentrations and the water quality parameters in different vegetation type zones of Lake Lingdang

\begin{tabular}{llll}
\hline & $\mathrm{NO}_{2}$ & $\mathrm{CH}_{4}$ & $\mathrm{CO}_{2}$ \\
\hline 菹草区 & $y=18.979+925.121 x\left(\mathrm{NO}_{2}^{-}-\mathrm{N}\right)-$ & $y=0.133+0.006 x(\mathrm{~T})-0.030 x\left(\mathrm{NO}_{3}^{-}-\mathrm{N}\right)$ & $y=32.958-1.008 x(\mathrm{~T})+2.203 x(\mathrm{DO})$ \\
$(n=13)$ & $5.508 x\left(\mathrm{NO}_{3}^{-}-\mathrm{N}\right)$ & $R^{2}=0.659(P<0.01)$ & $R^{2}=0.848(P<0.001)$ \\
& $R^{2}=0.908(P<0.001)$ & $y=37.128-4.160 x(\mathrm{pH})$ & $y=393.550-39.374 x(\mathrm{pH})-131.003 x(\mathrm{TP})$ \\
睡莲区 & $y=6.678+274.343 x(\mathrm{TP})$ & $R^{2}=0.556(P<0.01)$ & $R^{2}=0.608(P<0.05)$ \\
$(n=13)$ & $R^{2}=0.610(P<0.01)$ & $y=0.395+10.568 x\left(\mathrm{NO}_{2}^{-}-\mathrm{N}\right)$ & $y=84.629-6.311 x(\mathrm{D} 0)$ \\
莲藕区 & $y=-226.542+30.244 x(\mathrm{pH})$ & $R^{2}=0.379(P<0.05)$ & $R^{2}=0.615(P<0.01)$ \\
$(n=13)$ & $R^{2}=0.466(P<0.05)$ & & \\
\hline
\end{tabular}


与蕰草不同, 睡莲和莲藕在生长期叶面遮挡水面, 阻挡了阳光进人水面, 抑制了大气复氧和藻类的光 合作用; 而在秋冬季衰亡后, 由于温度较低, 微生物活性减弱, 其残体的分解过程较为缓慢, 水体长期处于 耗氧过程中, 使其 DO 浓度显著低于薄草区 (表 1), 并间接影响了水中温室气体的溶存浓度. P 虽然不直接 参与温室气体的产生和排放, 但作为水体中生物必需的营养元素, 支持着生物初级生产, 从而通过影响植 物生物量间接影响温室气体的排放 ${ }^{[23-24]}$. 睡莲区和莲藕区水体中 TP 浓度均显著高于蕰草区, 有利于植物 的生长和繁殖, 植物死亡后沉积到湖底, 为沉积物有机物的累积提供了丰富的易降解碳源, 同时加强了湖 泊底部的厌氧条件, 有利于 $\mathrm{CH}_{4}$ 和 $\mathrm{N}_{2} \mathrm{O}$ 的产生 ${ }^{[23]}$.

$\mathrm{pH}$ 也是影响温室气体排放的重要因子. 各植被区湖水中 $\mathrm{CO}_{2}$ 浓度与水体 $\mathrm{pH}$ 呈负相关, 且在睡莲区和 莲藕区 $\mathrm{CO}_{2}$ 浓度与 $\mathrm{pH}$ 呈显著负相关 (表 3), 这与其他研究者获得的结论相一致 ${ }^{[8]}$. 铃铛湖湖水偏碱性 (表 $1)$, 游离的 $\mathrm{CO}_{2}$ 易发生溶解, 由此导致 $\mathrm{CO}_{2}$ 浓度降低. 而 $\mathrm{pH}$ 对 $\mathrm{CH}_{4}$ 和 $\mathrm{N}_{2} \mathrm{O}$ 产生和排放的影响主要是通过影 响微生物的活性间接产生的 ${ }^{[25-26]}$, 铃铛湖湖水 $\mathrm{pH}$ 值在 8.21 9.48 之间波动, 产甲烷菌的活性随 $\mathrm{pH}$ 升高而 受到了抑制. 黄文敏等 ${ }^{[25]}$ 研究发现秋季香溪河水一气界面 $\mathrm{N}_{2} \mathrm{O}$ 交换通量与 $\mathrm{pH}$ 值呈显著正相关关系, 而也 有其他研究 ${ }^{[26-28]}$ 发现 $\mathrm{N}_{2} \mathrm{O}$ 的排放与 $\mathrm{pH}$ 值呈显著负相关关系. 但在本研究中, 莲藕区 $\mathrm{N}_{2} \mathrm{O}$ 浓度与 $\mathrm{pH}$ 呈显 著正相关关系 (表 3), 由于 $\mathrm{N}_{2} \mathrm{O}$ 的形成是多种氮循环过程共同作用的结果, 因此水体 $\mathrm{pH}$ 值对 $\mathrm{N}_{2} \mathrm{O}$ 排放的 影响还有待于进一步的研究和探讨.

铃铛湖上覆水中 DO 浓度 (表 1), 有利于 $\mathrm{CH}_{4}$ 的氧化, 且较高的 DO 浓度抑制了上覆水中的反硝化作 用，而各植被区上覆水中温室气体尤其是 $\mathrm{CH}_{4}$ 均具有较高的饱和度 (表 2), 说明水体深层和底泥中有机物 的微生物厌氧分解作用较为强烈, 导致上覆水中温室气体的溶存浓度较高 ${ }^{[2,8]}$. 水生植被衰亡腐烂后其残 体沉积在底泥中, 为产甲烷菌和反硝化细菌提供了丰富的底物和碳源 ${ }^{[4]}$, 有利于 $\mathrm{CH}_{4}$ 和 $\mathrm{N}_{2} \mathrm{O}$ 的产生和排 放. 本研究仅对各植被区上覆水理化性质进行了分析, 今后还需结合底泥理化性质进一步分析和探究不同 水生植被对水体温室气体产生和排放的影响机制.

\section{3 结论}

1) 铃铛湖不同植被区水域中 $\mathrm{DO} 、 \mathrm{TN} 、 \mathrm{TP}$ 和 $\mathrm{NO}_{3}^{-}-\mathrm{N}$ 平均浓度具有显著差异 $(P<0.05)$, 其中 $\mathrm{DO} 、 \mathrm{TN}$ 和 $\mathrm{NO}_{3}^{-}-\mathrm{N}$ 浓度表现为菹草区 $>$ 睡莲区>莲藕区，而 $\mathrm{TP}$ 浓度则正好相反，表现为莲藕区 $>$ 睡莲区>薄草区.

2) 铃铛湖水体中温室气体均处于过饱和状态, 表现为向大气排放温室气体; 不同植被区水体中 $\mathrm{N}_{2} \mathrm{O}$ 和 $\mathrm{CO}_{2}$ 浓度、饱和度和排放通量均无显著性差异 $(P>0.05), \mathrm{CH}_{4}$ 浓度、饱和度和排放通量均表现为睡莲区>莲 藕区>蕰草区.

3) 铃铛湖各植被区温室气体浓度不同程度地与水环境参数呈正/负相关关系, 但与 $\mathrm{NH}_{4}^{+}-\mathrm{N} 、 \mathrm{DIP}$ 浓度均 无显著相关性 $(P>0.05)$; 水生植物通过影响水体的理化性质对温室气体的产生和排放产生显著的差异性影 响, 表现为蕰草区湖水中温室气体浓度主要与 $\mathrm{NO}_{2}^{-}-\mathrm{N} 、 \mathrm{NO}_{3}^{-}-\mathrm{N} 、 \mathrm{~T}$ 和 $\mathrm{DO}$ 相关; 睡莲区相关参数为 $\mathrm{TP}$ 和 $\mathrm{pH}$; 莲藕区相关参数为 $\mathrm{pH} 、 \mathrm{NO}_{2}^{-}-\mathrm{N}$ 和 $\mathrm{DO}$.

\section{4 参考文献}

[ 1 ] Yang P, He Q, Huang J et al. Fluxes of greenhouse gases at two different aquaculture ponds in the coastal zone of southeaster China. Atmospheric Environment, 2015, 115: 269-277.

[ 2 ] Han Y, Zheng YF, Wu RJ et al. Greenhouse gases emission characteristics of Nanjing typical waters in spring. China Environment Science, 2013, 33(8): 1360-1371. [韩洋, 郑友飞, 吴荣军等. 南京典型水体春季温室气体排放特征研究. 中国环境科学, 2013, 33(8): 1360-1371.]

[ 3 ] Xiao QT, Hu ZH, Deng J et al. Effects of antiseptic on the analysis of greenhouse gas concentrations in lake water. Environmental Science, 2014, 35(1) : 356-364. [肖启涛, 胡正华, Deng J 等. 杀菌剂对湖泊水体温室气体浓度分析的影 响. 环境科学, 2014, 35(1): 356-364.]

[ 4 ] Zhang L, Zhang ZH, Gao Y et al. Effect of aquatic plants on emission of gases from eutrophic water. Journal of Ecology and Rural Environment, 2014, 30(6): 736-743. [张力, 张振华, 高岩等. 不同水生植物对富营养化水体释放气体 的影响. 生态与农村环境学报, 2014, 30(6): 736-743.] 
[ 5 ] Xing T, Li JX, Li BB et al. Effects of macrophytes on gaseous nitrogen emissions and nitrogen removal from sediments in a shallow eutrophic lake. Chinese Journal of Ecology, 2018, 37(3): 771-778. [邢涛, 李俊雄, 李涁涁等. 水生植物对草 型富营养化湖泊气态氮排放及沉积物氮去除的影响. 生态学杂志, 2018, 37(3) : 771-778.]

[6] Yang WJ. The primarily study and tests on annual eutrophicational changes of city lakes in Wuhan[Dissertation]. Wuhan: Huazhong Agricultural University, 2010. [杨文静. 武汉市内湖富营养化周年变化规律的监测及初步讨论 [ 学位论 文]. 武汉: 华中农业大学, 2010.]

[ 7 ] Yang WB. Colonization and ecological management of Potamogeton crispus in eutrophic lakes: A case study of Xuanwu Lake in Nanjing[Dissertation]. Nanjing: Nanjing Normal University, 2009. [ 杨文斌. 富营养化湖泊菹草的拓殖与生态 管理一以南京玄武湖为例 [ 学位论文]. 南京: 南京师范大学, 2009. ]

[ 8 ] Wen ZD, Song KS, Zhao Y et al. Seasonal variability of greenhouse gas emissions in the urban lakes in Changchun, China. Environmental Science, 2016, 37(1): 102-111. [温志丹, 宋开山, 赵莹等. 长春城市水体夏秋季温室气体排放 特征. 环境科学, 2016, 37(1): 102-111.]

[ 9 ] Jia L, Pu YN, Yang SJ et al. Analysis of greenhouse gas emission characteristics and their influencing factors in the algae zone of Lake Taihu. Environmental Science, 2018, 39(5): 2316-2329. [贾否, 蒲旖㻈, 杨诗俊等. 太湖藻型湖区 $\mathrm{CH}_{4} 、 \mathrm{CO}_{2}$ 排放特征及其影响因素分析. 环境科学, 2018, 39(5): 2316-2329.]

[10] Yan XC, Zhang ZQ, Ji M et al. Concentration of dissolved greenhouse gas and its influence factors in the summer surface water of eutrophic lake. J Lake Sci, 2018, 30(5): 1420-1428. DOI: 10.18307/2018.0523. [间兴成, 张重乾, 季铭等. 富营养化湖泊夏季表层水体温室气体浓度及其影响因素. 湖泊科学, 2018, 30(5) : 1420-1428.]

[11] Oliveira-Junior ES, Tang Y, Berg SJP et al. The impact of water hyacinth (Eichhornia crassipes) on greenhouse gas emission and nutrient mobilization depends on rooting and plant coverage. Aquatic Botany, 2018, 145: 1-9.

[12] Gao Y, Zhang F, Liu XH et al. Mediation of production and transportation of $\mathrm{N}_{2} \mathrm{O}$ in eutrophic water with the free-floating aquatic plant, Eichhornia crassipes. Acta Scientiae Circumastantiae, 2017, 37(3): 925-933. [高岩, 张芳, 刘新红等. 漂浮水生植物对富营养化水体中 $\mathrm{N}_{2} \mathrm{O}$ 产生及输移过程的调节作用. 环境科学学报, 2017, 37(3) : 925-933.]

[13] Liu W, Jiang X, Zhang Q et al. Has submerged vegetation loss altered sediment denitrification, $\mathrm{N}_{2} \mathrm{O}$ production and denitrifying microbial communities in subtropical lakes? Global Biogeochemical Cycles, 2018, 32: 1195-1207.

[14] Yu ZJ, Deng HG, Wang DQ et al. Nitrous oxide emissions in the Shanghai river network : implications for the effects of urban sewage and IPCC methodology. Global Change Biology, 2013, 19: 2999-3010.

[15] Ministry of Environmental Protection of the People's Republic of China, Editorial Board of Water and Wastewater Monitoring and Analysis Methods eds. Water and Wastewater Monitoring and Analysis Methods: 4th edition. Beijing: China Environmental Science Press, 2002. [ 国家环境保护总局《水和废水监测分析方法》编委会. 水和废水监测分析方法: 第 4 版. 北京: 中国环境科学出版社, 2002.]

[16] Wang D, Chen Z, Sun W et al. Methane and nitrous oxide concentration and emission flux of Yangtze Delta plain river net. Science in China: Series B: Chemistry, 2009, 52(5): 652-661.

[17] Sun WW, Wang DQ, Chen ZL et al. Methane and nitrous oxide concentration and emission flux of Yangtze Delta plain river net. Science in China: Series B: Chemistry, 2009, 39(2) : 165-175. [孙玮玮, 王东启, 陈振楼等. 长江三角洲平原 河网水体溶存 $\mathrm{CH}_{4}$ 和 $\mathrm{N}_{2} \mathrm{O}$ 浓度及其排放通量. 中国科学: B 辑: 化学, 2009, 39(2) : 165-175.]

[18] Wang JQ, Zheng YF, Wang GX. Diurnal variation of water quality around Potamogeton crispus population. Acta Ecologica Sinica , 2013, 33(4) : 1195-1203. [王锦旗, 郑有飞, 王国祥. 菹草种群内外水质日变化. 生态学报, 2013, 33(4): 1195-1203.]

[19] Zhang J, Deng HG, Wu AQ et al. Decomposition of Potamogeton crispus and its effect on the aquatic environment of Dongping. Acta Scientiae Circumstantiae, 2013, 33(9): 2590-2596. [张菊, 邓焕广, 吴爱琴等. 东平湖菹草腐烂分解及其 对水环境的影响. 环境科学学报, 2013, 33(9): 2590-2596.]

[20] Deng H, Zhang J, Chen S et al. Metal release/accumulation during the decomposition of Potamogeton crispus in a shallow macrophytic lake. Journal of Environmental Sciences, 2016, 42(4) : 71-78.

[21] Duc NT, Crill P, Bastviken D. Implications of temperature and sediment characteristics on methane formation and oxidation in lake sediments. Biogeochemistry, 2010, 100(1/2/3) : 185-196.

[22] Gudasz C, Bastviken D, Steger K et al. Temperature-controlled organic carbon mineralization in lake sediments. Nature, 2010, 466(7305) : 478-481. 
[23] Jiang XY, Zhang L, Yao XL. Greenhouse gas flux at reservoirs of Jiangxi Province and its influencing factors. J Lake Sci, 2017, 29(4) : 1000-1008. DOI: 10.18307/2017.0424. [姜星宇, 张路, 姚晓龙等. 江西省水库温室气体释放及其影 响因素分析. 湖泊科学, 2017, 29(4): 1000-1008.]

[24] Song HL, Liu XT, Wen BL. Greenhouse gases fluxes at water-air interface of aquaculture ponds in the Yellow River estuary. Ecology and Environmental Sciences, 2017, 26(9): 1554-1561. [宋红丽, 刘兴土, 文波龙. 黄河三角洲养殖塘水一 气界面通量特征. 生态环境学报, 2017, 26(9): 1554-1561.]

[25] Huang WM, Zhu KX, Zhao W et al. Diurnal changes in the greenhouse gases at water-air interface of Xiangxi River in autumn and their influencing factors. Environmental Sciences, 2013, 34(4) : 1270-1276. [黄文敏, 朱孔贤, 赵玮等. 香溪 河秋季水-气界面温室气体通量日变化观测及影响因素分析. 环境科学, 2013, 34(4) : 1270-1276.

[26] Yang P, Tong C. Emission paths and measurement methods for greenhouse gas fluxes from freshwater ecosystems: a review. Acta Ecologica Sinica, 2015, 35(20) : 6868-6880. [杨平, 全川. 淡水水生生态系统温室气体排放的主要途径及影 响因素研究进展. 生态学报, 2015, 35(20): 6868-6880.]

[27] Chang SQ, Wang DQ, Yu L et al. Greenhouse gas emission characteristics from urban rivers in Shanghai. Research of Environmental Sciences, 2015, 28(9) : 1375-1381. [常思琦, 王东启, 俞琳等. 上海城市河流温室气体排放特征及其影 响因素. 环境科学研究, 2015, 28(9) : 1375-1381.]

[28] Ma Y, Sun L, Liu C et al. A comparison of methane and nitrous oxide emissions from inland mixed-fish and crab aquaculture ponds. Science of the Total Environment, 2018, 637/638: 517-523. 